Daniel Martínez-Ávila, José Augusto Chaves Guimarães, and Isadora Victorino Evangelista. 2017. Epistemic communities in Knowledge Organization: An analysis of the NASKO meetings proceedings. NASKO, Vol. 6. pp. 113-123.

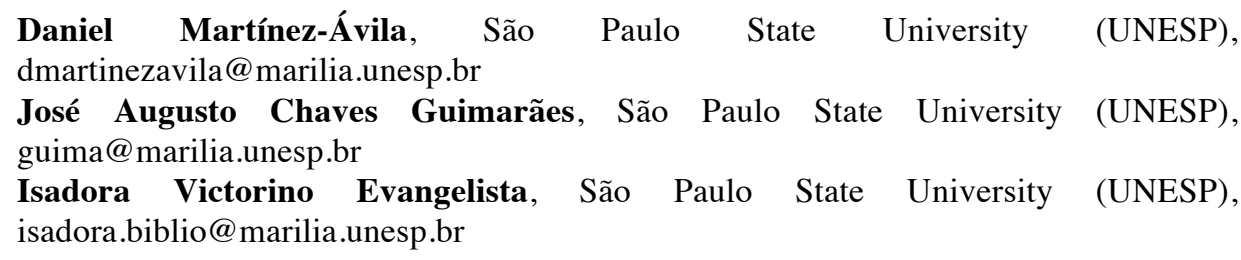

\title{
Epistemic communities in Knowledge Organization: An analysis of the NASKO meetings proceedings
}

\begin{abstract}
Epistemic communities can be understood as networks of knowledge-based experts that hold in common a set of principled and causal beliefs, have shared notions of validity, exchange knowledge, and shape, demarcate, and articulate the identities of present and future knowledge producers. In Knowledge Organization, epistemic communities have been likened to the term "domain" in the domain-analytic paradigm. Acknowledging the important role that ISKO C-US, the International Society for Knowledge Organization: Chapter for Canada and United States, plays in the international production of scientific knowledge, we aim to characterize this epistemic community based on the publications of the five North American Symposium on Knowledge Organization (NASKO) meetings proceedings. The results allow us to conclude that the ISKO C-US community is a productive, dialogical, and a continuously well-developed community with a well-balanced trajectory between an epistemological dimension, in search of its theoretical and methodological bases, and a social dimension, considering different cultural backgrounds. These aspects demarcate and shape the road for future research on knowledge organization
\end{abstract}

\section{Introduction}

Knowledge Organization $(\mathrm{KO})$ is concerned with the conceptualization of social practices and activities related to the access to knowledge, providing tools for the processing and management of the information use. KO covers phenomena related to the structure, disposition, access, and dissemination of knowledge that is produced, recorded, and socialized in such a way that others can appropriate it and create new knowledge, in an infinite helical movement (Barité 2001).

As a field with competitors and different approaches in the communication and exchange of knowledge (Hjørland 2008, 2016), it seems necessary to better understand the constitution and internal relations of the domain, an aspect that can be studied, among other means, by the identification of the epistemic communities. The study of the epistemic communities of areas that are in the process of consolidation, as it is the 
Daniel Martínez-Ávila, José Augusto Chaves Guimarães, and Isadora Victorino Evangelista. 2017. Epistemic communities in Knowledge Organization: An analysis of the NASKO meetings proceedings. NASKO, Vol. 6. pp. $113 Z^{123}$

case of $\mathrm{KO}$, has been proposed to measure their impact on society and the academia (Guimarães et al. 2015).

Epistemic communities can be understood as networks of knowledge-based experts that "not only hold in common a set of principled and causal beliefs but also have shared notions of validity and a shared policy enterprise. Their authoritative claim to policy-relevant knowledge in a particular domain is based on their recognized expertise within that domain" (Haas 1992, 16). Epistemic communities not only produce and disseminate knowledge, but they also, among other things, "shape, demarcate, and articulate the identities of present and future knowledge producers; and they shape individual and collective trajectories on which the latter navigate" (Meyer and Molyneux-Hodgson 2010). Epistemic communities influence the scientific knowledge that is produced, as well as the scientific field in which they are immersed.

In $\mathrm{KO}$, epistemic communities have been likened to the term "domain" in the domain-analytic paradigm (e.g., Mustafa El Hadi 2015), indeed, the aforementioned characteristics of epistemic community converges with the definitions of the related concepts of domain and discourse communities given by Smiraglia (2012, 111-112): "[a domain] must be a group with a coherent ontology, which implies also a shared epistemology [...] All [both domain, discourse community, and also invisible colleges] suggest some sort of social networking among participant scholars." However, Smiraglia also noted some differences between these concepts: "the concept of "domain" suggests intellectual boundaries, and the concept of "discourse community" suggests an active exchange of information." In this paper, as we focus on the configuration of an epistemic community in $\mathrm{KO}$, we work with the exchange of intellectual information between scholars (in the form of citations), an aspect that also shapes and conforms the domain.

Acknowledging the important role that ISKO C-US, the International Society for Knowledge Organization: Chapter for Canada and United States, has been playing in the international production of scientific knowledge, we aim to characterize this epistemic community based on the publications of the five North American Symposium on Knowledge Organization (NASKO) meetings proceedings. 
Daniel Martínez-Ávila, José Augusto Chaves Guimarães, and Isadora Victorino Evangelista. 2017. Epistemic communities in Knowledge Organization: An analysis of the NASKO meetings proceedings. NASKO, Vol. 6. pp. $1133_{3} 123$.

\section{Methodology}

Our approach to the study of the epistemic communities can be considered a domain analysis that combines the bibliometric, epistemological, and the study of structures and institutions in scientific communication approaches (Hjørland 2002).

We worked with the universe of 78 papers published in the proceedings of the five NASKO meetings held thus far $(2007,2009,2011,2013$, and 2015), focusing on the authors, affiliations, and references of each. First, we analyzed the authors in order to characterize the actors in the epistemic community based on their interrelations (coauthorships) and institutional contexts. Then, we analyzed the sources (cited authors) in order to determine their influences and theoretical convergences (exchanges and sharing of information) using co-citation analysis as a domain analytic technique (Castanha \& Grácio 2014). For the citation analysis, two of the papers were discarded as they did not include references. This made a sample of 76 papers and a total of 1,226 cited authors (excluding self-citations and corporate entities). For the determination of the number of most cited authors we used the authors with at least five citations, an average of one citation per conference, resulting in 43 authors. For the graphical representation of the networks we used the software Pajek.

\section{Results and discussion}

There is a total of 82 authors in the universe of the 78 papers. 52 papers $(66 \%)$ belong to authors with only US affiliations, 16 papers (20\%) belong to authors with only Canadian affiliations, and four papers (6\%) belong to authors with affiliations of countries outside North America (Brazil and the Netherlands). In six papers (8\%), there was a collaboration between authors with affiliations of two or more countries (USChina, US-Brazil-Spain, US-Spain, and US-Canada). The most productive authors are: Smiraglia (seven papers), Tennis (five papers), Dousa and Green (four papers each), Beak, Campbell, Fox, Guimarães, Kipp, La Barre, and Pimentel (three papers each), Edwards, Hoffman, Hudon, Loehrlein, Martínez-Ávila, Milani, Olson, Pattuelli, Hajibayova, and Szostak (two papers each), and a long tail of 48 authors with just one paper. Figure 1 shows the most productive authors (in green) in relation to the authors that participated in their papers (in red). The most productive authors in red on the 


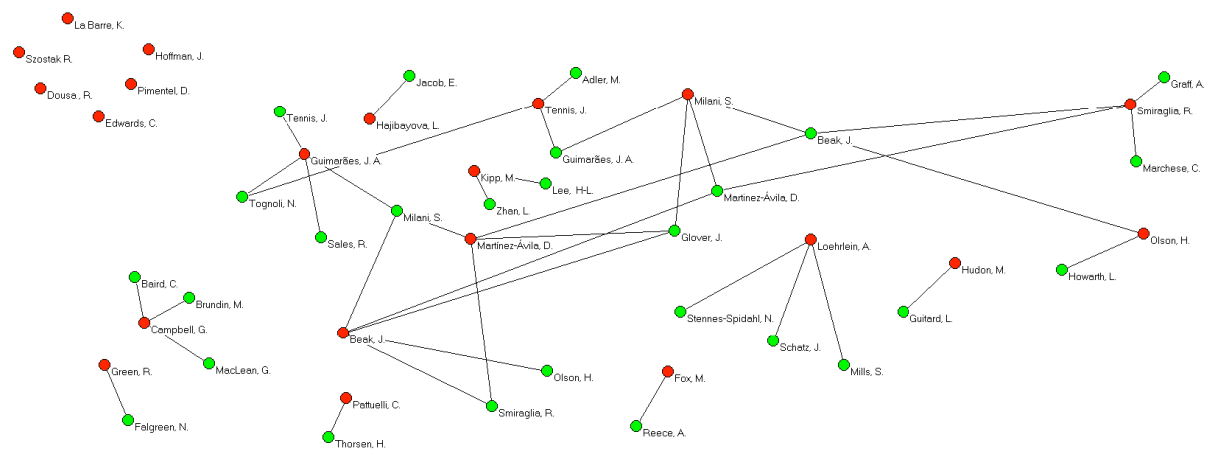

Figure 1: Co-authorship network of the NASKO proceedings

The most productive affiliations, considering only those authors with a minimum of three papers, are: University of Wisconsin-Milwaukee (17 papers), University of Washington (seven papers), São Paulo State University (five papers), University of Western Ontario (six papers), and Indiana University - Bloomington, Université de Montréal, Texas Woman's University, and University of British Columbia (three papers each).

The most cited authors are: Hjørland (49 citations), Olson, (35 citations), Ranganathan (23 citations), Mai (19 citations), Svenonius (16 citations), Beghtol (18 citations), Albrechtsen (13 citations each), Cutter and Miksa (11 citations each), Gnoli, and Tennis (11 citations each), Berman, Broughton, and Smiraglia (10 citations eachs), Bates, Feinberg, Gardin, López-Huertas, Navarro, and Star (nine citations each), Berners-Lee, Jacob, and Vickery (eight citations each), Bowker, Dewey, Foucault, La Barre, and Taylor (seven citations each), Barsalou, Bliss, Chan, Foskett, Joudrey, Kaiser, Kwaśnik, and Pejtersen (six citations each), and Andersen, Campbell, Green, Rosch, Saracevic, Tillett, and Wilson (five citations each). Of this sample of 371 citations, 237 (64\%) correspond to authors with affiliations in the US or Canada. This reveals that the NASKO community is very productive - and recognized - in relation to the KO literature and its influence in future research. On the other hand, the presence of 
Daniel Martínez-Ávila, José Augusto Chaves Guimarães, and Isadora Victorino Evangelista. 2017.

Epistemic communities in Knowledge Organization: An analysis of the NASKO meetings proceedings.

NASKO, Vol. 6. pp. $1135^{123}$

$36 \%$ of the authors of foreign affiliation also reveals a concern with an international enrichment of the research, drawing on authors from a wide range of countries, notably European (Denmark, France, Italy, Spain, and United Kingdom), and also India.

Figure 2 shows the citation network of the most productive authors (in red) and the most cited authors (in green). Some of the strongest connections include HoffmanOlson, Guimarães-Gardin, Smiraglia-Hjørland, Smiraglia-Navarro, Martínez-ÁvilaNavarro, Dousa-Hjørland, Milani-López-Huertas, Fox-Olson, Tennis-Ranganathan, and La Barre-Ranganathan. Among these relations it is possible to identify not only schools of thought and academic interests, but also, in some cases, adviser-student relationships. In the case of Tillet, she appears with no relational ties and isolated in the network as she was not cited by any of the most productive authors.

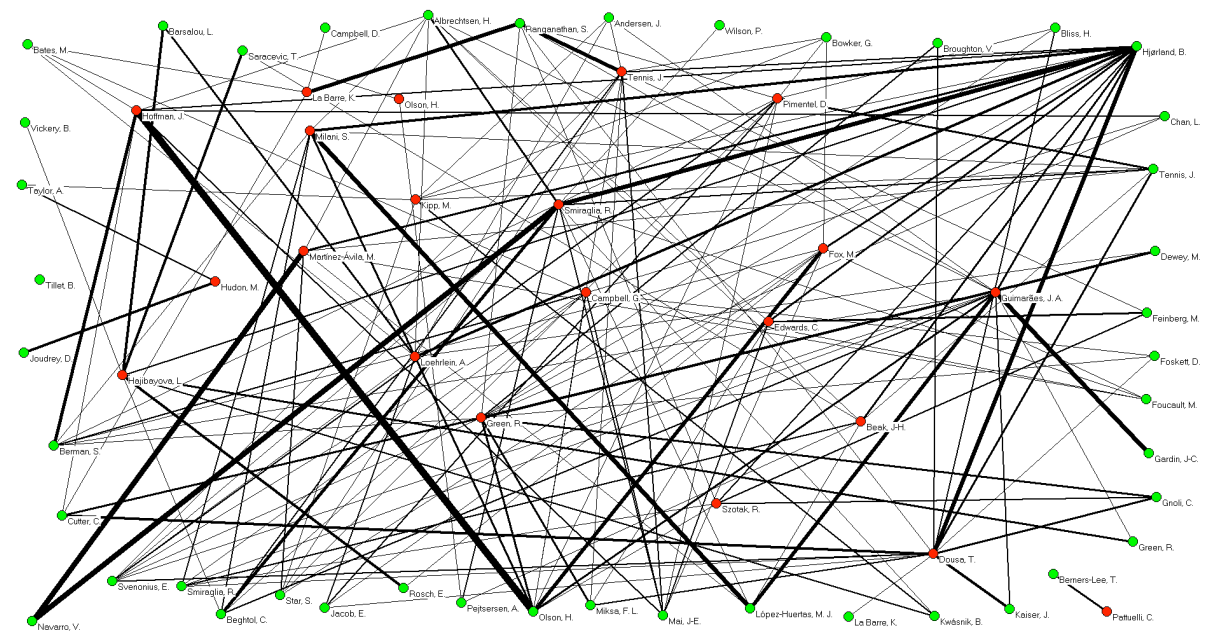

Figure 2: Citation network of the NASKO proceedings

There are six authors that simultaneously stand as the most productive and most cited ones: Hope Olson (with three papers and 30 citations), Richard Smiraglia (with seven papers and nine citations), Joseph Tennis (with six papers and five citations), Kathryn La Barre (with three papers and seven citations), Rebecca Green (with four papers and five citations), and Grant Campbell (with three papers and five citations). Thus, there is an epistemic community in NASKO that not only shapes and affects the 
Daniel Martínez-Ávila, José Augusto Chaves Guimarães, and Isadora Victorino Evangelista. 2017. Epistemic communities in Knowledge Organization: An analysis of the NASKO meetings proceedings. NASKO, Vol. 6. pp. $1136^{123}$

literature, but also it is recognized by peers. This community is well distributed regionally in organizations such as the University of Wisconsin-Milwaukee (US), University of Washington (US), University of Illinois (US), the Library of Congress (US), and University of Western-Ontario (Canada).

It should be noted that 16 authors (39\% of the selected group), summing 227 citations (49\% of their citations), namely Albrechtsen, Beghtol, Berman, Campbell, Feinberg, Foucault, Hjørland, Kwaśnik, López-Huertas, Mai, Olson, Rosch, Smiraglia, Star, Tennis, and Wilson, show a strong tie with the socio-cognitive and cultural dimension of $\mathrm{KO}$ in their publications. This aspect seems to flag this dimension as a key area for $\mathrm{KO}$ and as a research trend. Other examples of this include: previous North American initiatives such as the three conferences on "The Ethics of Knowledge Organization," organized by Hope Olson and Richard Smiraglia at the University of Wisconsin-Milwaukee in 2009, 2012, and 2015; the theme "Culture and identity in knowledge organization" of the 2008 ISKO International meeting, held in Montréal and led by Clément Arsenault and Joseph Tennis; as well as the theme of the 2013 NASKO Conference: "Transition cultures, transition KO."

It is also interesting to note that Hjørland and Olson together gather $18 \%$ of all citations. The third most cited author, Ranganathan, received about half of the citations of each of them. The analysis of the citations of these two authors also reveals eight papers (four by each), that accumulate $54 \%$ of the total citations received by Olson and $46 \%$ of the total citations received by Hjørland, suggesting their seminal character for the NASKO epistemic community and the KO field.

The citations received by Hjørland are distributed among 26 works, mostly concentrated on four works: seven citations refer to domain analysis (Hjørland \& Albrechtsen 1995), and twelve citations refer to the epistemological dimension of KO, in relation to its conceptual aspects (Hjørland 2003, 2008) and more specifically to concept theory (Hjørland 2009).

As for the citations received by Olson, these are distributed among 17 works, mostly concentrated on four works: seven citations refer to the power to name (Olson 2002), five citations refer to need for a classificatory space for marginalized communities (Olson 1998), four citations refer to the question of "objectivity" in KO (Olson \& 
Daniel Martínez-Ávila, José Augusto Chaves Guimarães, and Isadora Victorino Evangelista. 2017. Epistemic communities in Knowledge Organization: An analysis of the NASKO meetings proceedings. NASKO, Vol. 6. pp. 113 123.

Schlegl 2001), and three citations refer to the contribution of feminism to KO (Olson 2007). All these citations fall under the cultural dimension of KO.

Although the co-citation network is very dense, it is possible to identify some groups of authors that are being co-cited (Figure 3). Within the network, Navarro is an exceptional case as he appears in the network due to the total number of citations that he received (in co-citation with Foucault) but he was only cited by one paper (Martínez-Ávila \& Smiraglia 2013). Hjørland, Olson, and Ranganathan are key actors in the network as they are on the list of the most cited authors. Hjørland was cited in practically every paper analyzed and co-cited with 39 out of the 43 most cited authors. In the case of Svenonius, although she is not among the most cited authors, she was cocited with 36 of the most cited authors, something it is also relevant. In relation to the content of the co-cited papers, six papers co-cite Hjørland and Olson in relation to cultural approaches from a socio-cognitive perspective: five papers on sex and gender in KO, sexual health, feminism, and diversity (Hoffman 2009; Fox 2011; McTavish \& Fortier 2011; Milani \& Guimarães 2011; Szostak 2013), and a paper on the theoretical basis of knowledge organization systems (Dousa 2015). This central role of Hjørland and Olson in the socio-cognitive and cultural dimension of KO literature is seconded by the fact that two thirds of the citations received by Hjørland and Olson occurred in the NASKO meetings of 2011 and 2013, whose themes leaned to this dimension, in search of an expansion of horizons and the recognition of a cultural dynamism in KO. 
Daniel Martínez-Ávila, José Augusto Chaves Guimarães, and Isadora Victorino Evangelista. 2017. Epistemic communities in Knowledge Organization: An analysis of the NASKO meetings proceedings. NASKO, Vol. 6. pp. 113 123.

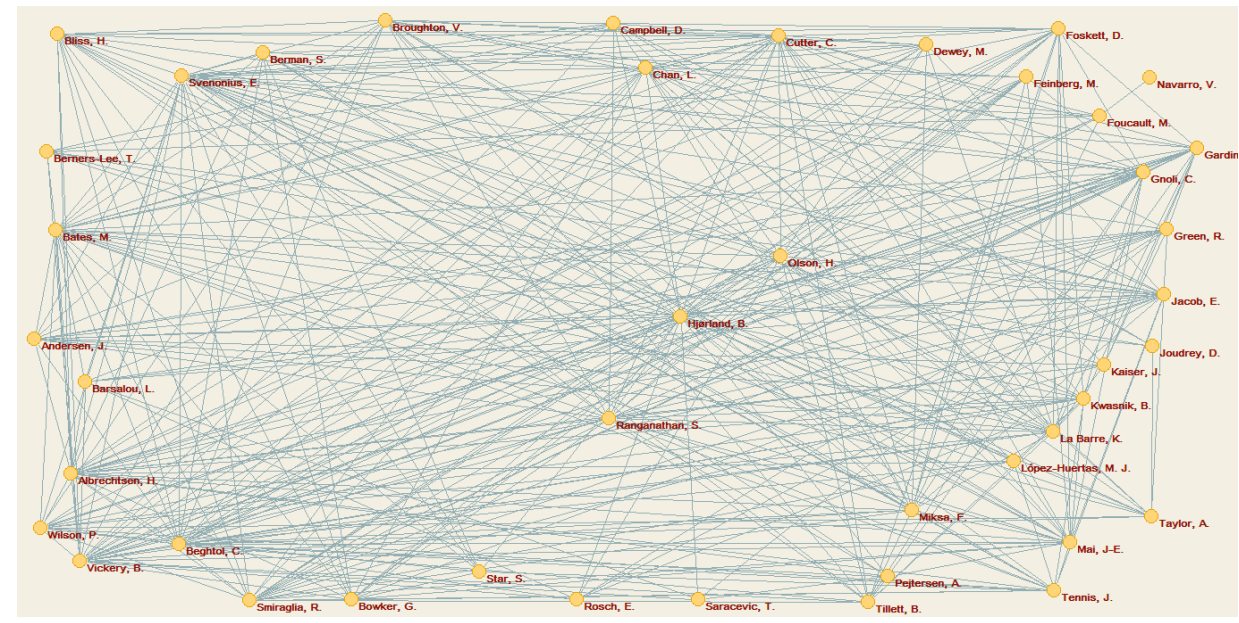

Figure 3: co-citation network of the NASKO proceedings

\section{Conclusion}

ISKO C-US - the International Society for Knowledge Organization: Chapter for Canada and United States - has been paving its scientific trajectory for five events so far, whose proceedings allowed the identification of an epistemic community with strong cohesion and dialogues (exchange of information in the form of citations). These characteristics are reflected in the fact that there is a core of authors that are considerably productive (citing authors), and, at the same time, sources of information (cited authors). This shows the consolidation of a scientific community in which individuals network, share a common set of knowledge, and also shape the domain. Within the community, there is also an international openness and sensibility that does not exclude the participation and influence of individuals outside the NASKO context (as evidenced by the citations to foreign authors).

In terms of affiliations, the following universities stand out as the most active ones in the community: University of Wisconsin-Milwaukee, University of Washington, University of Western Ontario, Indiana University - Bloomington, Université de Montréal, Texas Woman's University, and University of British Columbia. As for the authors that provide more information to the scientific production of the community, Birger Hjørland and Hope Olson appear as key sources with $18 \%$ of all received citations, and also a high rate of co-citations, especially in relation to the theoretical- 
Daniel Martínez-Ávila, José Augusto Chaves Guimarães, and Isadora Victorino Evangelista. 2017. Epistemic communities in Knowledge Organization: An analysis of the NASKO meetings proceedings. NASKO, Vol. 6. pp. 113 g123.

conceptual and socio-cognitive aspects of KO (Hjørland) and the cultural aspects of KO (Olson).

These aspects allow us to conclude that the ISKO C-US community is a productive, dialogical, and a continuously well-developed community with a well-balanced trajectory between an epistemological dimension, in search of its theoretical and methodological bases, and a social dimension, considering different cultural backgrounds. These aspects demarcate and shape the road for future research on knowledge organization. Thus, it is concluded that the ISKO C-US community has been playing a very important role among the ISKO chapters.

\section{References}

Barité, Mario. 2001. "Organización del conocimiento: Un nuevo marco teóricoconceptual en Bibliotecología y Documentación" In Educação, universidade e pesquisa, edited by K. Carrara. Marília: Oficina Universitária; São Paulo: FAPESP, pp. 35-60.

Castanha, Renata Cristina Gutierres and Maria Cláudia Cabrini Grácio. 2014. "Bibliometrics contribution to the metatheoretical and domain analysis studies" Knowledge Organization 41: 171-174.

Dousa, Thomas M. 2015. "Categories in Charles A. Cutter's Systems of Subject Cataloging and Bibliographical Classification" Presented at NASKO 2015, North American Symposium on Knowledge Organization, June 18-19, 2015, Los Angeles, California. Available http://www.iskocus.org/NASKO2015proceedings/Dousa.pdf.

Fox, Melodie J. 2011. "Prototype Theory: An Alternative Concept Theory for Categorizing Sex and Gender?" In Proceedings from North American Symposium on Knowledge Organization, Vol. 3, Toronto, Canada, edited by Richard P. Smiraglia, pp. 151-159.

Guimarães, José Augusto Chaves, Daniel Martínez-Ávila and Bruno Henrique Alves. 2015. "Epistemic communities in knowledge organization: an analysis of research trends in the Knowledge Organization journal." Presented at Knowledge Organization - making a difference: The impact of knowledge organization on society, scholarship and progress. ISKO UK biennial conference 13th - 14th July 2015, 
Daniel Martínez-Ávila, José Augusto Chaves Guimarães, and Isadora Victorino Evangelista. 2017. Epistemic communities in Knowledge Organization: An analysis of the NASKO meetings proceedings. NASKO, Vol. 6. pp. $1130^{23}$

London. $\quad$ http://www.iskouk.org/content/epistemic-communities-knowledgeorganization-analysis-research-trends-knowledge-organization.

Haas, Peter M. 1992. "Epistemic communities and international policy coordination." International Organization 46(1): 01-35..

Hjørland, Birger. 2002. "Domain analysis in information science: eleven approaches - traditional as well as innovative" Journal of Documentation 58(4): 422-462.

Hjørland, Birger. 2003. "Fundamentals of Knowledge Organization." Knowledge Organization 30: 87-111.

Hjørland, Birger. 2008. "What is knowledge organization (KO)?" Knowledge Organization 35: 86-101.

Hjørland, Birger. 2009. "Concept theory." Journal of the American Society for Information Science and Technology 60(8): 1519-1536.

Hjørland, Birger. 2016. "Knowledge Organization (KO)." Knowledge Organization 43: 475-484.

Hjørland, Birger and Hanne Albrechtsen. 1995. "Toward a new horizon in information science: Domain-analysis." Journal of the American Society for Information Science 46(6): 400-425.

Martínez-Ávila, Daniel, and Richard P. Smiraglia. 2013. "Revealing Perception: Discourse Analysis in a Phenomenological Framework.” In Proceedings from North American Symposium on Knowledge Organization, Vol. 4. University of WisconsinMilwaukee.

Avaliable

http://www.iskocus.org/NASKO2013proceedings/MartinezAvila_Smiraglia_Revealing _Perception.pdf.

McTavish, Jill and Alexandre Fortier. 2011. A domain-analytic perspective on sexual health in LCSH and RVM. In Proceedings from North American Symposium on Knowledge Organization, Vol. 3, Toronto, Canada, edited by Richard P. Smiraglia, pp. 83-93.

Meyer, Morgan and Susan Molyneux-Hodgson. 2010. "Introduction: the dynamics of epistemic communities.” Sociological Research Online 15(2): 14.

Milani, Suellen Oliveira and José Augusto Chaves Guimarães. 2011. "Biases in knowledge representation: an analysis of the feminine domain in Brazilian indexing 
Daniel Martínez-Ávila, José Augusto Chaves Guimarães, and Isadora Victorino Evangelista. 2017. Epistemic communities in Knowledge Organization: An analysis of the NASKO meetings proceedings. NASKO, Vol. 6. pp. $1131^{123 .}$

languages." In Proceedings from North American Symposium on Knowledge Organization, Vol. 3, Toronto, Canada, edited by Richard P. Smiraglia, pp. 94-104.

Mustafa El Hadi, Widad. 2015. "Cultural Interoperability and Knowledge Organization Systems.” In Organização do Conhecimento e Diversidade Cultural, edited by Kosé Augusto Chaves Guimarães and Vera Dodebei. Marília: ISKO-Brasil; FUNDEPE, pp. 575-606.

Olson, Hope A. 1998. "Mapping beyond Dewey's boundaries: constructing classificatory space for marginalized knowledge domains" Library Trends 47(2): 233254.

Olson, Hope A. 2002. The power to name: Locating the limits of subject representation in libraries. Dordrecht: Kluwer Academic.

Olson, Hope A. 2007. "How we construct subjects: A feminist analysis." Library Trends 56(2): 509-541.

Olson, Hope A. and Rose Schlegl. 2001. "Standardization, objectivity, and user focus: A meta-analysis of subject access critiques." Cataloging \& Classification Quarterly 32(2): 61-80.

Smiraglia, Richard P. 2012. "Epistemology of Domain Analysis" In Cultural Frames of Knowledge, edited by Richard P. Smiraglia and Hur-Li Lee. Würzburg, Germany: Ergon, pp. 111-124..

Szostak, Rick. 2013. "Classification for Diversity." In Proceedings from North American Symposium on Knowledge Organization, Vol. 4. University of WisconsinMilwaukee.

Avaliable http://iskocus.org/NASKO2013proceedings/Szostak_ClassifyingForDiversity.pdf 